\title{
Administrações Orais do Látex da Hancornia speciosa Gomes não aumentam a neoformação óssea*
}

\section{Oral Administrations of Hancornia speciosa Gomes Latex Do Not Increase Bone Neoformation}

\author{
Pedro Duarte Novaes ${ }^{1}$ \\ ${ }^{1}$ Departamento de Morfologia, Faculdade de Odontologia de \\ Piracicaba, Universidade Estadual de Campinas, Piracicaba, SP, Brasil \\ 2 Departamento de Saúde Bucal, Escola Técnica Qualificar, \\ Florianópolis, SC, Brasil \\ ${ }^{3}$ Departamento de Ciências Exatas, Escola Superior de Agricultura \\ Luiz de Queiroz, Universidade de São Paulo, Piracicaba, SP, Brasil \\ Rev Bras Ortop 2019;54:692-696.
}

Francielly Andressa Felipetti ${ }^{10}$ Rafaela Mariano Bereta ${ }^{2}$ Sônia Maria Stefano Piedade ${ }^{3}$
Endereço para correspondência Francielly Andressa Felipetti, Rua Eugênio de Bona Castelan, 120, apto 502, Criciúma, SC, 88801-640, Brasil (e-mail: fafelipetti@gmail.com).

\section{Resumo \\ Palavras-chave \\ - apocynaceae \\ - hematoxilina \\ - histologia \\ - látex \\ - osso e ossos \\ - terapias complementares}

Objetivo Este trabalho objetivou avaliar o efeito sistêmico do látex de $H$. speciosas obre a neoformação óssea.

Métodos Para isso, o látex foi coletado e diluído a 3\% e a 50\%. Um total de 28 ratos Wistar foi submetido a cirurgia para a criação de um defeito de $5 \mathrm{~mm}$ de diâmetro no osso parietal. Esse experimento foi conduzido em dois períodos distintos: 1 e 2. Para cada período, os ratos foram divididos em 3 grupos: Grupo Controle, Grupo Látex3 e Grupo Látex50 que receberam, respectivamente, administrações diárias de $0,5 \mathrm{~mL}$ de água destilada, látex a $3 \%$ e látex a $50 \%$ por gavagem, via oral. Os ratos dos períodos 1 e 2 foram eutanasiados, respectivamente, 15 e 30 dias após a cirurgia e a calvária foi coletada. Os resultados foram analisados utilizando os testes ANOVA e Tukey; o nível de significância estabelecido foi 0,05 .

Resultados Mostramos que, em cada período analisado, os grupos experimentais tiveram a mesma quantidade de osso neoformado no defeito da calvária.

Conclusão Portanto, concluímos que administrações diárias e orais do látex de $\mathrm{H}$. speciosa a $3 \%$ e a $50 \%$ durante um período de 15 e 30 dias não contribui para o aumento da área do osso neoformado no defeito da calvária.

Objective The present work aimed to evaluate the systemic effect of $H$. speciosa latex on bone neoformation.

\footnotetext{
* Trabalho feito no Departamento de Morfologia, Faculdade de Odontologia de Piracicaba (FOP), Universidade Estadual de Campinas (UNICAMP), Piracicaba, SP, Brasil.
}

recebido

04 de Junho de 2018

aceito

08 de Agosto de 2018
DOI https://doi.org/

$10.1055 / \mathrm{s}-0039-1697019$. ISSN 0102-3616.
Copyright $(2019$ by Sociedade Brasileira License terms de Ortopedia e Traumatologia. Published by Thieme Revinter Publicações Ltda, Rio de Janeiro, Brazil 


\section{Keywords \\ - apocynaceae \\ - hematoxylin \\ - histology \\ - latex \\ - bone and bones \\ - complementary therapies}

Methods For this, the latex was collected and diluted to $3 \%$ and $50 \%$. A total of 28 Wistar rats were submitted to surgery to create a $5 \mathrm{~mm}$ diameter defect in the parietal bone. This experiment was conducted in 2 different periods: 1 and 2. For each period, the rats were divided into 3 groups: Control Group, Latex3 Group, and Latex50 Group, which received, respectively, daily administrations of $0.5 \mathrm{~mL}$ of distilled water, latex to $3 \%$ and latex to $50 \%$ by gavage, orally. The rats of periods 1 and 2 were euthanized, respectively, 15 and 30 days after the surgery, and the calvaria was collected. The results were analyzed using the ANOVA and Tukey tests; the significance level was 0.05 . Results We show that, in each analyzed period, the experimental groups had the same amount of newly formed bone in the calvaria defect.

Conclusion We conclude that daily and oral administrations of $H$. speciosa latex to $3 \%$ and to $50 \%$ over a period of 15 and 30 days does not contribute to the increase of the area of the newly formed bone in the calvaria defect.

\section{Introdução}

O osso é um tecido conjuntivo mineralizado altamente dinâmico. As principais células do osso, como osteoblastos, osteoclastos e osteócitos, são essenciais para sua remodelação. ${ }^{1,2}$ Nos estágios iniciais da produção óssea, os osteoblastos depositam a matriz orgânica, liberam vesículas com estoque de cálcio (Ca) e induzem a degradação do pirofosfato, liberando íons de fosfato. ${ }^{2-4}$ Fosfato e Ca formam cristais de hidroxiapatita e mineralizam a matriz óssea, formando o novo osso. ${ }^{1}$ Através deste processo de remodelação óssea, o osso pode se regenerar espontaneamente após o estabelecimento de fraturas, lesões ou defeitos. ${ }^{5}$ No entanto, a regeneração fisiológica é incapaz de restaurar a integridade óssea em defeitos ósseos extensos, nos quais o processo de reparo deve ser apoiado por algumas terapias complementares. ${ }^{6,7}$

O látex obtido do tronco da Hevea brasiliensis (uma árvore nativa brasileira conhecida como Seringueira) pode ser um biomaterial inovador para reparo ósseo. Alguns experimentos que foram realizados com este produto incluem a reparação óssea de cavidades dentárias em ratos, ${ }^{8}$ regeneração guiada de calvária de coelhos, ${ }^{6}$ a osseointegração de implantes dentários em cães, ${ }^{9}$ e reparo ósseo de um defeito crítico da calvária de ratos. ${ }^{10,11}$

O látex extraído do tronco de Hancornia speciosa Gomes (outra árvore nativa brasileira conhecida como Mangabeira, pertencente à família Apocynaceae) também demonstrou potencial de reparo ósseo. $O$ grupo de pesquisa da Faculdade de Odontologia de Piracicaba (FOP) da Universidade Estadual de Campinas (UNICAMP), demonstrou que a aplicação tópica de látex de $H$. speciosa no defeito da calota craniana de ratos Wistar aumentou a área do osso neoformado nas bordas do defeito. $^{12}$

Algumas comunidades localizadas no nordeste do Brasil produziram um suco leitoso chamado "leite da mangaba" a partir do látex do tronco da H. speciosa. Levantamentos etnobotânicos confirmaram o uso desse suco lácteo para tratamento terapêutico de fraturas ósseas. ${ }^{13}$ No entanto, até o momento, nenhum estudo foi realizado para confirmar esse efeito.

Em resumo, esses achados nos motivaram a investigar o potencial terapêutico do látex de H. speciosa. Por isso, este estudo relata o efeito sistêmico do látex de $H$. speciosa na neoformação óssea em ratos Wistar.

\section{Materiais e Métodos}

\section{Coleta e Análise de Látex}

O látex da $H$. speciosa foi coletado na cidade de Mata de São João, Bahia, Brasil $\left(12^{\circ} 27^{\prime} 42^{\prime} \mathrm{S} 37^{\circ} 56^{\prime} 38^{\prime} \mathrm{O} 69 \mathrm{NE}\right)$ no verão. Uma amostra deste foi depositada na Escola Superior de Agricultura Luiz de Queiroz (ESALQ) da Universidade de São Paulo (USP) e recebeu o número ESA 121.402. Após perfurar 10 troncos de árvore, $250 \mathrm{~mL}$ do látex que pingou foram coletados em um recipiente esterilizado e misturados com água destilada para obter uma solução de látex a $3 \%$ e outra a $50 \%$. As soluções foram armazenadas em seringas, protegidas da luz e estocadas a $4^{\circ} \mathrm{C}$.

\section{Animais}

Foram utilizados 28 ratos Wistar (peso corporal médio de $390 \mathrm{~g}$; idade de 10 semanas). Os ratos foram alojados em gaiolas individuais sob condições controladas de temperatura e luz (ciclo claro/escuro de 12/12 h). Todos os animais receberam ração e água ad libitum. Antes da cirurgia, os ratos foram anestesiados com injeção intraperitoneal de $80 \mathrm{mg} / \mathrm{Kg}$ de Ketamina (Dopalen, SespoIndústria e Comércio Ltda., Paulínia, SP) e $8 \mathrm{mg} / \mathrm{Kg}$ de Xilazina (Rompun, Bayer SA, São Paulo, SP, Brasil). A cirurgia consistiu na criação de defeito crítico no osso parietal esquerdo da calvária (diâmetro de $5 \mathrm{~mm}$ ) usando broca trefina montada em motor odontológico de baixa rotação. Após a cirurgia, os ratos foram administrados por via intramuscular com $2 \mathrm{mg} / \mathrm{mL}$ de cloridrato de tramadol (Tramal, Grunenthal do Brasil Pharmaceutical Ltda, São Paulo, SP, Brasil) e repousaram por 24 horas. Esse experimento foi conduzido em 2 períodos distintos: 1 e 2 . Para o período 1 , os ratos foram divididos em 3 grupos: Grupo Controle 1 (C1, $n=4$ ), Grupo Látex 31 (L31, $n=4$ ) e Grupo Látex 501 (L501, $n=5$ ) que receberam, respectivamente, administrações diárias de $0,5 \mathrm{~mL}$ de água destilada, látex a $3 \%$ e látex a $50 \%$ por gavagem, via oral, durante 15 dias. Para o período 2, os ratos foram divididos em 3 grupos: Grupo Controle $2(\mathrm{C} 2, n=5)$, Grupo Látex $32(\mathrm{~L} 32, n=5)$ e Grupo Látex $502(\mathrm{~L} 502, n=5)$ que 
receberam, respectivamente, administrações diárias de $0,5 \mathrm{~mL}$ de água destilada, látex a $3 \%$ e látex a $50 \%$ por gavagem, via oral, durante 30 dias. Os ratos dos períodos 1 e 2 foram eutanasiados, respectivamente, 15 dias e 30 dias após a cirurgia. Após a eutanásia, a calvária foi coletada para análise. Todos os procedimentos foram aprovados pelo Comitê de Ética em Uso de Animais (CEUA) com o número de protocolo 3427-1.

\section{Análise Histológica}

Clivagem das Amostras e Processamento Histológico A calvária foi fixada em solução de formol e submetida ao processamento histológico convencional. ${ }^{14}$ Primeiro, a calvária foi seccionada transversalmente e apenas a porção óssea foi obtida. Posteriormente, a calvária foi descalcificada com solução de PLANK, por 1 semana com 2 trocas diárias. Após a descalcificação, a calvária foi clivada e apenas a região do defeito ósseo foi preservada para posterior processamento. Em seguida, o defeito ósseo da calvária foi desidratado, diafanizado e embebido em parafina para obtenção dos blocos. ${ }^{14}$

\section{Confecção das Lâminas Histológicas}

Uma vez obtidos os blocos de parafina, secções coronais da calvária foram coletadas. Todas as secções tinham $6 \mu \mathrm{m}$ de espessura. Como padrão, oito secções consecutivas dos blocos da calvária foram, primeiramente, coletadas; 2 lâminas histológicas foram preparadas e 15 secções foram, finalmente, descartadas; estes passos foram realizados repetidamente até serem obtidas 20 lâminas. Todas as lâminas foram coradas com hematoxilina e eosina e observadas ao microscópio de luz.

\section{Análises Descritivas e Histomorfométricas}

As lâminas foram fotografadas usando o programa Optica View 7 e as imagens foram registradas com ampliação de 100x para todo o defeito ósseo da calvária. Essas imagens foram analisadas por um único examinador usando o programa Image J (National Institutes of Health, Bethesda, MD, EUA). Os processos de reparação da calvária foram demonstrados por meio de análise descritiva. A área óssea neoformada em todo o defeito ósseo da calvária foi examinada por análise histomorfométrica. Para isso, uma régua milimétrica foi primeiramente fotografada com ampliação 100x e depois medida de ponta a ponta; a distância em pixels foi registrada; a distância conhecida foi estabelecida de acordo com o tamanho da régua $(1 \mathrm{~mm})$; e a unidade de comprimento foi ajustada em milímetros. Esta informação foi registrada em cada foto do defeito da calvária para definir escala. Por fim, desenhou-se uma linha marcando todo o osso recémformado dentro do defeito da calvária e, finalmente, calculou-se a área do osso novo. Os valores quantificados foram comparados entre os grupos.

\section{Análise Estatística}

Os dados foram analisados usando o software $\mathrm{R}$ ( $\mathrm{R}$ Core Team). Os testes de Bartlett e de Shapiro-Wilk foram utilizados para verificar o desvio dos pressupostos. Uma vez que a homogeneidade de variância e distribuição normal foram confirmadas, o teste de análise de variância (ANOVA, na sigla em inglês) e de Tukey foram usados para comparar os grupos do período 1 e 2 , separadamente. 0 nível de significância foi estabelecido em $5 \%(p<0,05)$.

\section{Resultados}

\section{Análise Histológica Descritiva do Defeito Ósseo da Calvária}

A técnica histológica convencional utilizando microscopia de luz é amplamente utilizada para análise de reparo ósseo. Essa técnica permite uma análise descritiva do tecido e a mensuração da área dos componentes de interesse (histomorfometria). ${ }^{15}$ Utilizamos essas análises para avaliar o osso neoformado no defeito da calvária.

A análise descritiva revelou um estágio semelhante de reparo ósseo entre os grupos C1, L31 e L501 e entre os grupos C2, L32 e L502 ( - Figura 1). Trabéculas mineralizadas do osso recém-formado se estenderam das bordas do osso basal em direção ao centro do defeito. Observamos vários osteócitos aprisionados na matriz óssea e espaços medulares cheios de células sanguíneas ao longo das trabéculas. Numerosos osteoblastos ativos foram notados ao redor das trabéculas. Tecido conjuntivo abundante, amplamente vascularizado, preencheu as porções centrais do defeito.

\section{Análise Histológica Histomorfométrica da Calvária}

A análise histomorfométrica da calvária está representada na - Figura 2. Medimos a área do osso neoformado em cada grupo. Os resultados mostraram que a quantidade de osso novo nos grupos L31 e L501 foi semelhante à do grupo C1. Da mesma forma, a quantidade de osso novo nos grupos L32 e L502 foi semelhante à do grupo C2. Esses dados são coerentes com aqueles da análise descritiva.

\section{Discussão}

Este trabalho investigou o efeito sistêmico do látex de $H$. speciosa sobre a neoformação óssea em ratos Wistar.

Em resumo, o osso é um tecido conjuntivo mineralizado altamente dinâmico, e suas principais células (osteoblastos, osteoclastos e osteócitos) são essenciais para sua remodelação. ${ }^{1,2}$

Na presença de uma fratura, os eventos relacionados à cicatrização resultam na formação de um novo osso. ${ }^{16}$ Nos estágios iniciais da produção óssea, os osteoblastos depositam a matriz orgânica, formando um tecido conhecido como osteoide. Então, os osteoblastos liberam vesículas com reservas de Ca que são degradadas por enzimas para liberar esse íon na matriz recém-depositada. Os osteoblastos também secretam fosfatase alcalina, uma enzima que degrada o pirofosfato, liberando íons de fosfato. ${ }^{2,4,17}$ Fosfato e Ca formam cristais de hidroxiapatita e mineralizam a matriz óssea, formando o novo osso. ${ }^{1}$ No presente estudo, a análise histológica mostrou trabéculas do osso neoformado ao longo do defeito da calvária. Segundo a literatura, na presença de uma fratura, os eventos relacionados à cicatrização resultam na formação de um calo ósseo que progride para interligar as duas extremidades. ${ }^{16}$ 


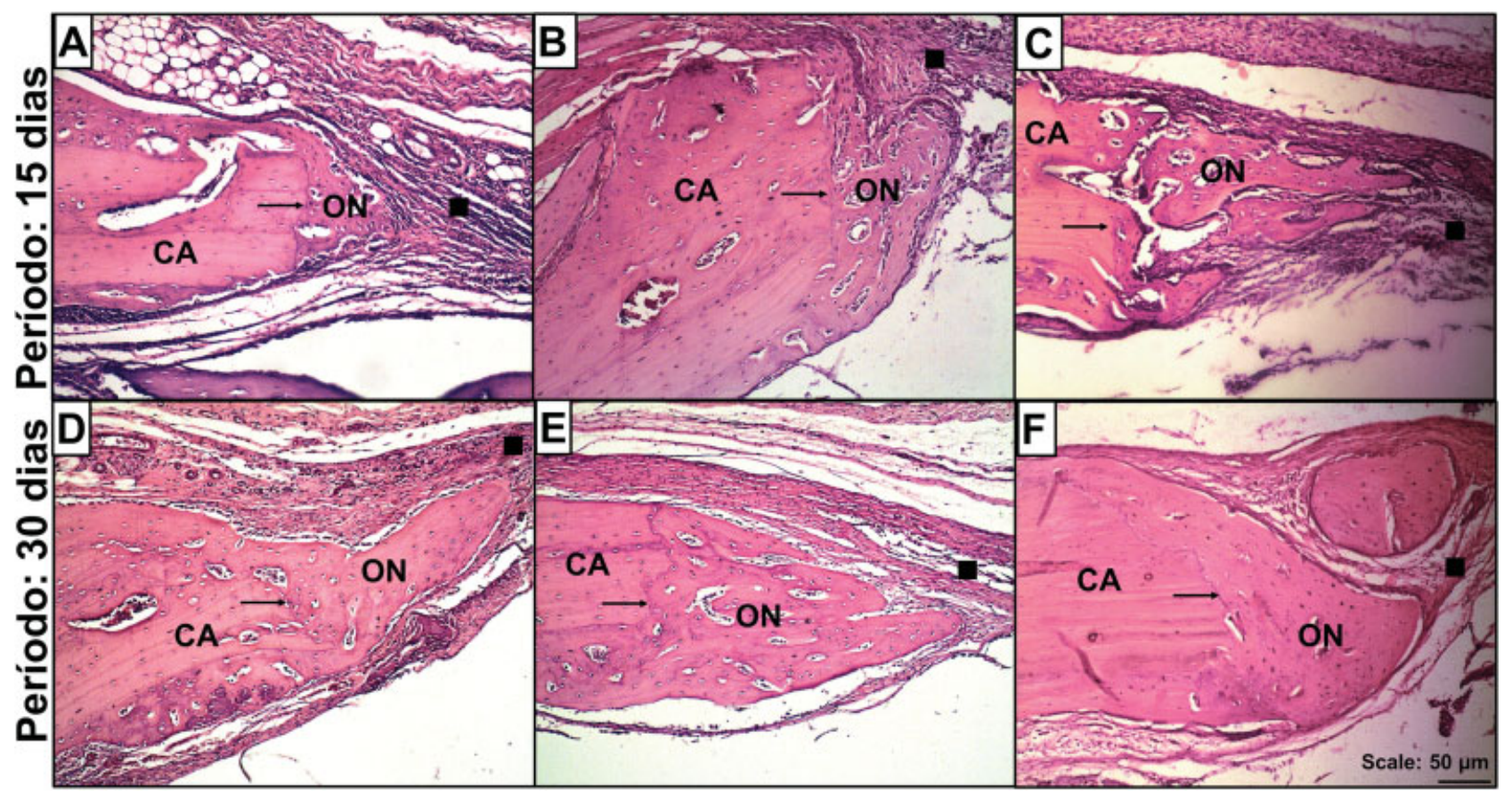

Fig. 1 Neoformação óssea no defeito da calvária. Fonte: Do próprio autor. Nota: Estas são imagens representativas de uma das bordas do defeito da calvária, analisadas nos períodos de 15 e 30 dias. Corte coronal. As imagens A, B e C representam, respectivamente, os grupos C1, L31 e L501. As imagens D, E e F representam, respectivamente, os grupos C2, L32, L502. Observe o osso novo formado estendendo-se das bordas em direção ao centro do defeito em todos os grupos. CA, calvária; ON, osso novo; $\rightarrow$, bordas do defeito; $\mathbf{\square}$, tecido conjuntivo propriamente dito. (Hematoxilina e Eosina, 100X).

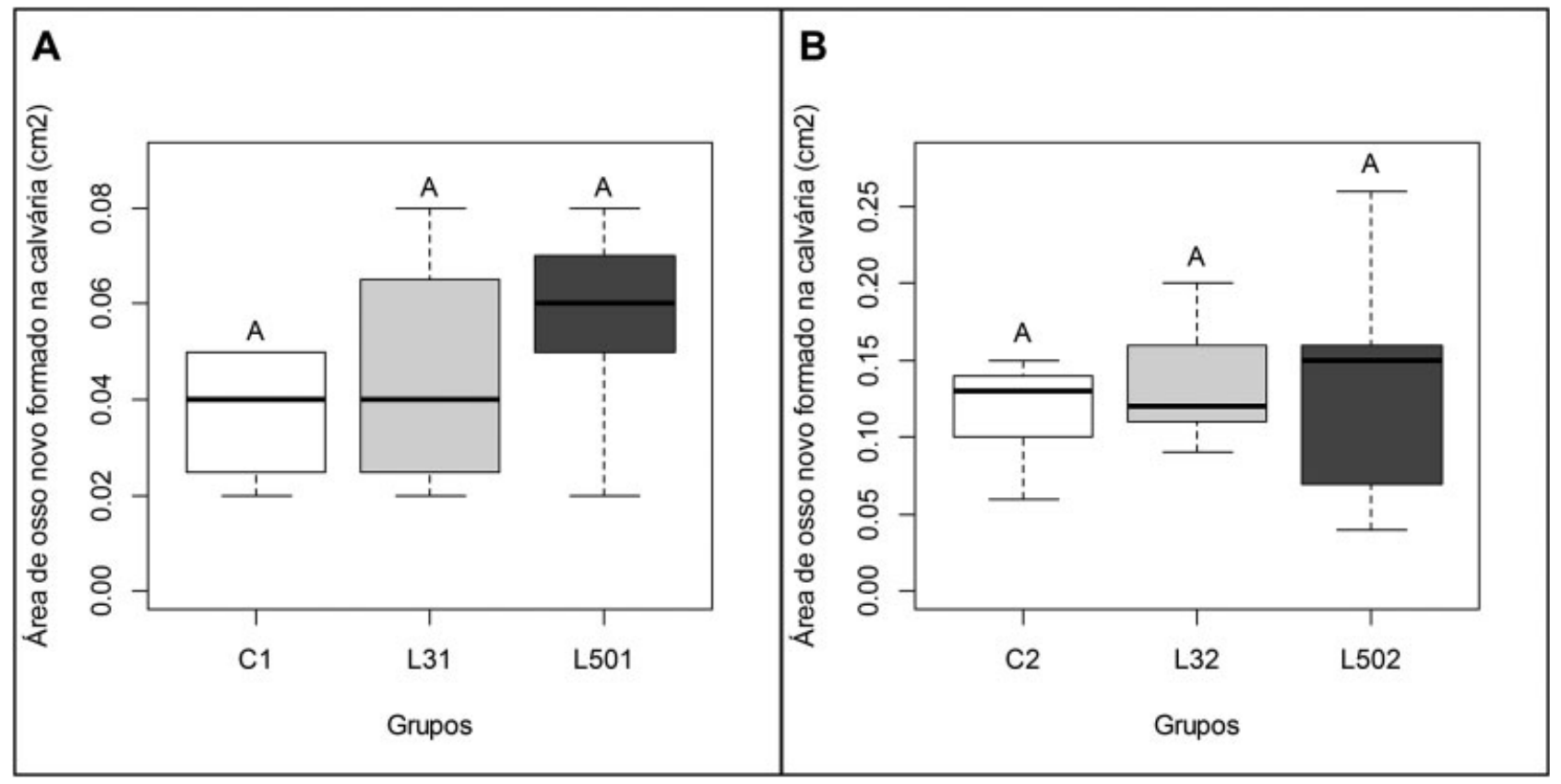

Fig. 2 Área de osso novo formado no defeito da calvária de ratos. Fonte: Do próprio autor. Nota: O gráfico A ilustra a área de osso neoformado no defeito da calvária após o período 1 (15 dias). C1, Grupo Controle; L31, Grupo Látex 3\%, L501, Grupo Látex 50\%. O gráfico B ilustra a área de osso neoformado no defeito da calvária após o período 2 (30 dias). C2, Grupo Controle; L32, Grupo Látex 3\%, L502, Grupo Látex 50\%. Letras equivalentes indicam que não há diferença estatisticamente significante entre os grupos, de acordo com o teste de análise de variância, com $p<0.05$.

Esses conceitos explicam porque o processo de reparo ósseo começou nas bordas do osso basal em direção ao centro do defeito da calvária em todos os grupos.

A análise histomorfométrica revelou que as administrações orais de látex a 3\% e a 50\% não aumentaram a área do osso neoformado no defeito da calvária, mesmo após 15 e 30 dias de tratamento. Por outro lado, a literatura confirma que há um aumento na área do osso neoformado tanto na calvária $^{12}$ quanto no alvéolo mandibular ${ }^{8}$ de ratos tratados com látex natural usando aplicações locais do produto. Esse 
efeito pode ser atribuído à presença de alguns fitoquímicos no látex. Dos santos Neves et al ${ }^{12}$ identificaram que o látex de H. speciosa contém ácido clorogênico e naringenina-7-Oglicosídeo. Há evidências de que esses compostos estimulam as atividades osteoblásticas. ${ }^{18,19}$ Os osteoblastos ativos secretam uma grande quantidade de fosfatase alcalina e osteocalcina, moléculas importantes para a deposição de Ca e mineralização óssea (Florence et al., 2017). Assim, esses fitoquímicos podem aumentar a densidade mineral óssea e melhorar a microarquitetura óssea. ${ }^{18,19}$ Possivelmente, nossos resultados são diferentes dos encontrados na literatura por causa das distintas vias de administrações do produto. No presente estudo, avaliamos o efeito do produto administrado oralmente enquanto que os estudos descritos na literatura demonstram resultados do produto quando administrado pela via tópica. Para confirmar o efeito da administração oral do látex na neoformação óssea, outras doses precisam ser avaliadas em estudos futuros. E ainda, a composição química do osso neoformado também precisa ser analisada para entender a crença popular sobre o benefício de consumir leite de mangaba diariamente para o tratamento de fraturas. ${ }^{13}$

\section{Conclusão}

No presente artigo, descobrimos que administrações diárias e orais do látex de $H$. speciosa a $3 \%$ e a $50 \%$ durante um período de 15 e 30 dias não contribuiu para o aumento da área do osso neoformado no defeito da calvária. Para confirmar outros efeitos deste látex sobre a massa óssea, diferentes doses do produto precisam ser testadas e a composição química do osso neoformado precisa ser avaliada em estudos futuros. Dessa forma, poderemos entender a crença popular sobre o benefício de consumir leite de mangaba diariamente para o tratamento de fraturas.

\section{Conflitos de Interesses}

Os autores não têm conflitos de interesses a declarar.

\section{Agradecimentos}

Os autores agradecem ao Conselho Nacional de Desenvolvimento Científico e Tecnológico (CNPq), número 141226/2014-5 pelo apoio dado ao presente estudo.

\section{Referências}

1 Raggatt LJ, Partridge NC. Cellular and molecular mechanisms of bone remodeling. J Biol Chem 2010;285(33):25103-25108
2 Valenti MT, DalleCarbonare L, Mottes M. Osteogenic Differentiation in Healthy and Pathological Conditions. Int J Mol Sci 2016;18 (01):E41

3 Florence NT, Huguette ST, Hubert DJ, et al. Aqueous extract of Peperomia pellucida (L.) HBK accelerates fracture healing in Wistar rats. BMC Complement Altern Med 2017;17(01):188

4 Guyton AC, Hall JE. Text book of medical physiology. 11th ed. Philadelphia: Elsevier Saunders; 2006

5 Thurairajah K, Broadhead ML, Balogh ZJ. Trauma and Stem Cells: Biology and Potential Therapeutic Implications. Int J Mol Sci 2017;18(03):E577

6 Ereno C, Guimarães SA, Pasetto S, et al. Latex use as an occlusive membrane for guided bone regeneration. JBiomed Mater Res A 2010;95(03):932-939

7 Walmsley GG, Ransom RC, Zielins ER, et al. Stem Cells in Bone Regeneration. Stem Cell Rev 2016;12(05):524-529

8 Balabanian CA, Coutinho-Netto J, Lamano-Carvalho TL, Lacerda SA, Brentegani LG. Biocompatibility of natural latex implanted into dental alveolus of rats. J Oral Sci 2006;48(04):201-205

9 ManfrinArnez MF, Xavier SP, Pinto Faria PE, et al. Implant osseointegration in circumferential bone defects treated with latexderived proteins or autogenous bone in dog's mandible. Clin Implant Dent Relat Res 2012;14(01):135-143

10 Issa JP, Defino HL, Pereira YC, et al. Bone repair investigation using rhBMP-2 and angiogenic protein extracted from latex. Microsc Res Tech 2012;75(02):145-152

11 Issa JP, Defino HL, Sebald W, et al. Biological evaluation of the bone healing process after application of two potentially osteogenic proteins: an animal experimental model. Gerodontology 2012;29 (04):258-264

12 Dos Santos Neves J, Franchin M, Rosalen PL, et al. Evaluation of the osteogenic potential of Hancorniaspeciosa latex in rat calvaria and its phytochemical profile. J Ethnopharmacol 2016;183:151-158

13 Silva JF Junior. A cultura da mangaba. Rev Bras Frutic 2006;26(01): $1-192$

14 Molinaro EM, Caputo L, Amendoeira R. Conceitos e Métodos para a formação de profissionais em laboratórios de saúde. Rio de JaneiroEPSJV2009. [acesso em 2018 maio 31]. Disponível em: www.fiocruz.br/ioc/media/Livropoli.pdf

15 Gomes PS, Fernandes MH. Rodent models in bone-related research: the relevance of calvarial defects in the assessment of bone regeneration strategies. Lab Anim 2011;45(01):14-24

16 Lin Z, Fateh A, Salem DM, Intini G. Periosteum: biology and applications in craniofacial bone regeneration. JDent Res 2014; 93(02):109-116

17 Florencio-Silva R, Sasso GR, Sasso-Cerri E, Simões MJ, Cerri PS. Biology of Bone Tissue: Structure, Function, and Factors That Influence Bone Cells. BioMed Res Int 2015;2015:421746

18 Li F, Sun X, Ma J, et al. Naringin prevents ovariectomy-induced osteoporosis and promotes osteoclasts apoptosis through the mitochondria-mediated apoptosis pathway. Biochem Biophys Res Commun 2014;452(03):629-635

19 Zhou RP, Lin SJ, Wan WB, et al. Chlorogenic Acid Prevents Osteoporosis by Shp2/PI3K/Akt Pathway in Ovariectomized Rats. PLoS One 2016;11(12):e0166751 